\title{
Conspiracy Thinking in Europe and America: A Comparative Study
}

\author{
Annemarie S. Walter and Hugo Drochon \\ School of Politics and International Relations \\ University of Nottingham
}

\begin{abstract}
:
What explains conspiracy thinking in Europe and America? This is the first and largest comparative study of conspiracy thinking to date, presenting findings using a representative sample of 11,523 respondents in 9 countries. First, it shows that the overall level of conspiracy thinking in Europe is equal to or slightly lower than the US, contradicting the notion that conspiracy theories is an especially American phenomenon. Second, people more inclined to conspiracy thinking position themselves towards the right of the political spectrum, engage in magical thinking, feel distrust towards public officials and reject the political system. Finally, we find that - surprisingly - the country context in which respondents reside has hardly any effect as predictor of levels of conspiracy thinking or as a moderator of individual-level determinants. Heterogeneity in conspiratorial thinking seems to be largely a function of individual traits.
\end{abstract}

Keywords: Conspiracy Theory, Conspiracy Thinking, Misinformation, Europe, United States

Funder: Leverhulme Trust

Declaration of Conflicting Interests: None

Acknowledgments: We would like to thank the Leverhulme Trust, through the 'Conspiracy and Democracy' research project at CRASSH, Cambridge, for funding the survey. Thanks also to Hugo Leal and to Joel Rogers de Waal of YouGov for helping design it and carry it out. We thank Professor Cees van der Eijk for his methodological advice, and the participants of the Comparative Research in Political Communication panel at the Fifth Conference of the International Journal of Press/Politics for their comments. Special thanks to Charles Pattie and to two anonymous reviewers for their insightful comments and queries that helped clarify and strengthen the piece. 


\section{Introduction}

From JFK to the X-Files to $9 / 11$, and now with a president who famously launched his political career with the 'birther' movement (Drochon, 2018), conspiracy theories are often perceived to be an especially American affliction, and this alleged exceptionalism has been reinforced by the field of cultural and American studies (Knight 2001, 2002; Melley 2000; Fenster 2008). But Europeans, at least going back to the Protocols of the Elders of Zion, have their own tradition. So, who is more likely to believe in conspiracy theories?

With the current rise of fake news and misinformation, the study of conspiracy theories is gaining increased attention. And far from being an amusing peccadillo, belief in conspiracy theories is linked to health risks, negative attitudes and prejudices towards groups in society, political radicalization, political violence, political disengagement and diminishing support for public policies, such as measures against climate change and vaccination (Douglas et al., 2019; van Prooijen and Douglas, 2018). Following Smallpage et al. (2020), we define a Conspiracy Theory as 'a proposed explanation of events or circumstances (past, present or future) which cites as the primary cause a conspiracy. Conspiracy theories could be either true or false, and, in most circumstances, contradict the proclamations of epistemological authorities'. Conspiracy Beliefs, therefore, are those specific conspiracy theories that individuals will say are true. Finally, Conspiracy Thinking, what is sometimes also referred to as 'conspiracy ideation' or 'conspiracy mentality', is a stable predisposition that drives individuals to see events as the product of a conspiracy.

People are not equally prone to conspiracy thinking, so what explains people's propensity to conspiracy thinking? Most work on conspiracy beliefs examines a single context, primarily the United States (Enders and Smallpage, 2018, for non-US single country studies see e.g. Mancosu et al., 2017; Jasinskaja-Lahti and Jetten, 2019; Krouwel et al., 2017; Sidiqui, 2018; Swami, 2012; and Hogg et al., 2017). However, even when studies are conducted in different contexts, many are based on different concepts, operationalizations and analytical approaches, thereby making systematic comparison problematic (Nyhan and Zeithoff, 2018 are the exception). The lack of comparative work raises important questions: to what extent are findings context-specific, and how does context affect people's belief in conspiracy theories? To develop a general theory of conspiracy thinking, we need work examining conspiracy belief in different contexts, not only to verify the general applicability of findings but also to formulate and test theories on how context characteristics interact with individuals' characteristics affecting their conspiracy thinking (Douglas et al., 2019; van Prooijen and Douglas, 2018).

In this paper we present the first cross-national representative sample survey of conspiracy beliefs across 8 European countries (Sweden, France, Germany, United Kingdom, Portugal, Italy, Poland, Hungary) and the United States, analyzing data of 11,523 respondents collected by YouGov in August 2018. This study contributes to the field in various ways. To begin, it is the first and largest integrated comparative study of conspiracy beliefs in the US and Europe to date. Second, it assesses the ways in which these beliefs are interconnected and consequently the structure of conspiracy belief systems. Third, it tests for the first time the universality of individual-level predictors explaining conspiracy thinking, thereby testing the external validity of findings of previous single country studies. Finally, it offers the first exploration of the importance of country-level and crosslevel predictors for explaining conspiracy thinking. Taken together, these contributions are a fundamental step towards developing a broader theory of conspiracy thinking.

We find that to explain people's propensity to conspiracy thinking, we first have to look at individual-level predictors as the effects of country-level and cross-level predictors are surprisingly limited. As such: the propensity to conspiracy thinking almost appears like an anthropological constant. This appears to replicate psychological work that takes this view as its premise, but contradicts a basic ontological assumption of the social sciences that people's attitudes and behaviour are affected by the context that they live in. We demonstrate people's proneness to conspiracy thinking to be particularly conditional on ideological position, magical thinking, trust in 
public figures and attitude towards the political system. Moreover, contrary to both the popular view and the one professed by American and cultural studies, we find that these 8 European countries have similar or slightly lower overall levels of conspiracy thinking compared to the United States: Europeans and Americans are as likely to believe in conspiracy theories as each other.

First, we discuss the literature on conspiracy thinking and individual-level, country-level and cross-level predictors, which leads to our hypotheses. Second, we present our data, analytical design and operationalization of our variables. We then present and discuss the results, and end by drawing conclusions and implications for further study of conspiracy thinking.

\section{Who believes in conspiracy theories?}

What explains people's tendency towards conspiracy thinking in Europe and America? Conspiracy thinking is a property that varies from individual to individual. The notion of conspiracy thinking is based on the finding that people who already believe in a particular conspiracy theory are more likely to believe in others that are not necessarily related or may even be contradictory (Douglas et al. ,2019; Swami et al., 2011; Swami and Furnham, 2012; Wood et al., 2012).

Numerous studies have been conducted identifying characteristics and attitudes that explain belief in specific conspiracy theories and/or a general tendency towards conspiracy thinking (Douglas et al. 2019). These studies have looked at personality traits (e.g. Swami et al., 2011; Darwin et al., 2011), sociodemographic factors (e.g. Freeman and Bentall, 2017; Stempel, et al., 2007; Hogg et al., 2017), political ideology (e.g. Uscinski and Parent, 2014; van Prooijen et al., 2015; Krouwel et al., 2017; Galliford and Furnham, 2017), religious and supernatural beliefs (e.g. Oliver and Wood, 2014; Galliford and Furnham, 2017; Jasinskaja-Lahti and Jetten, 2019), media exposure (e.g. Mulligan and Habel, 2012; Einstein and Glick, 2015; Warner and Neville-Shepard, 2014) and politico-economic exclusion (e.g. Hofstadter, 1996; Uscinski and Parent, 2014; Drochon, 2018). We will test various forms of these theories in a comparative perspective.

First of all, we look at the role of sociodemographic variables. Some studies find that conspiracy believers are more likely to be male (Freeman and Bentall, 2017; Hogg et al., 2017; Galliford and Furnham, 2017), other studies claim that conspiracy believers are more likely to be female (Mancuso et al., 2017; Stempel et al, 2007), and still others find that gender does not matter at all (Uscinski and Parent, 2014; Enders and Smallpage, 2019). Research suggests that those who are unmarried (Freeman and Bentall, 2017), unemployed (Freeman and Bentall, 2017; Hogg et al., 2017), younger (Goertzel, 1994; Stempel et al., 2007; Galliford and Furnham, 2017) and/or poorly educated are more likely to engage in conspiracy thinking (Mancosu et al., 2017; Uscinski and Parent, 2014; Freeman and Bentall, 2017; Bogart and Bird, 2003; Oliver and Wood, 2014; van Prooijen, 2017; Douglas et al., 2016; Galliford and Furnham, 2017; Hollanders, 2018), although again not all studies find a link between education and conspiracy thinking (Goertzel, 1994; Galliford and Furnham, 2017; Enders and Smallpage, 2019).

How gender, employment, marital status and age are linked to conspiracy thinking is somewhat undertheorized. Substantially more theory can be found on how education is linked to conspiracy thinking. First of all, people with low levels of education might have lower analytical skills (van Prooijen, 2017). Analytical thinking is negatively related to belief in conspiracy theories, as analytical skills enable people to evaluate conspiracy theories more critically, in particular conspiracy theories that defy logic and are not supported by evidence (Swami et al., 2014). An alternative explanation is that those with lower educational qualifications would be more inclined to attribute agency and intentionality in circumstances when it does not exist and thus have a stronger tendency to conspiracy thinking (Douglas et al., 2016). Finally, highly educated people feel more in control of their environment and are therefore less likely to engage in conspiracy thinking (van Prooijen, 2017). On the basis of these findings we formulate the following hypothesis: 
Education Hypothesis (H1): we expect conspiracy thinking to be dependent on citizens' level of education, whereby the higher the education level, the lower people's propensity to conspiracy thinking.

After examining the link between conspiracy thinking and various sociodemographic variables, we look at how people's attitudes matter for conspiracy thinking. Conspiracy thinking is often thought to be connected to people's ideology, although not all studies find that link (Dieguez et al., 2015). Several studies have found conspiracy thinking to be stronger at the political extremes (van Prooijen et al., 2015; Krouwel et al., 2017). Although all kinds of people engage in conspiracy thinking, conspiracy thinking is according to some stronger on the far right than the far left (van Prooijen et al., 2015; Krouwel et al., 2017; Galliford and Furnham, 2017; Linden et al. 2020). The reason for this might be that people on the right are more likely to have personality predispositions that stimulate conspiracy thinking, such as low tolerance for uncertainty and a desire for simple solutions and order (Jost et al., 2003, van Prooijen et al., 2015). The link between ideological extremity and conspiracy thinking is contested by some US studies that argue that conspiracy thinking is stronger among individuals who consider themselves independents or associate with third parties (non-Democrats and Republicans) (Uscinski and Parent, 2014; Uscinski et al., 2016). Subsequently, we formulate the following hypotheses:

Rightwing Hypothesis (H2): we expect people's propensity to conspiracy thinking to be conditional on their ideological position, whereby the more people perceive themselves as positioned towards the right of the political spectrum, the higher their propensity to conspiracy thinking.

Ideological Extremity Hypothesis (H3): we expect people's propensity to conspiracy thinking to be conditional on the extremity of their ideological position, whereby people who perceive themselves as positioned on the ideological extremes of the political spectrum have a higher propensity to conspiracy thinking than respondents who perceive themselves in the centre of the political spectrum.

Conspiracy thinking has been found to be associated with supernatural beliefs such as religious beliefs (e.g., Oliver and Wood, 2014; Mancuso et al., 2017; Galliford and Furnham, 2017; Jasinskaja-Lahti and Jetten, 2019) and belief in the paranormal (e.g., Swami and Furnham, 2012; Swami et al., 2011), but there are exceptions (Freeman and Bentall, 2017). People who hold supernatural beliefs tend to be more superstitious and conspiracy thinking shows similarities with belief in an entity that is all-powerful (Jasinskaja-Lahti and Jetten, 2019). Conspiracy thinking is therefore associated with so-called magical thinking, which is the willingness to believe in 'unseen, intentional and malevolent forces to explain an event, instead of directly seen or observable ones' (Oliver and Wood, 2014: 953). Consequently, we formulate the following hypothesis:

Magical Thinking Hypothesis (H4): we expect people's propensity to conspiracy thinking to be conditional on their degree of magical thinking, whereby people who have a high level of magical thinking have a greater tendency to conspiracy thinking.

It is also argued that conspiracy thinking is associated with people who feel powerless and excluded (Hofstadter, 1996; Uscinski and Parent, 2014; Drochon, 2018), however others dispute this view and argue that any ordinary citizen can become a conspiracy theorist (e.g. Radnitz and Underwood, 2017). Uscinski and Parent (2014) argue that in particular people who do not feel that their interests are represented within the political system are likely to believe in conspiracy theories. Consequently, we formulate the following hypothesis:

Representation Within the Political System Hypothesis: we expect people's tendency to conspiracy thinking to be dependent on the extent that they feel represented within the political system, 
whereby people who do not feel represented within the political system are more inclined to conspiracy thinking than people who do feel represented within the political system.

Another indicator of political exclusion than not feeling represented within the political system is overall distrust in political institutions and their representatives. Various studies have found political distrust to be associated with a stronger propensity to conspiracy thinking (Imhoff and Bruder, 2014) - conspiracy theorists tend to reject the 'official line' (Wood et al., 2012) - and political trust with a lower propensity to conspiracy thinking (Jasinskaja-Lahti and Jetten, 2019; Einstein and Glick, 2015; Swami et al., 2010, 2011), although not all studies agree (Mancuso et al., 2017). We formulate the following hypothesis:

Institutional Trust Hypothesis: we expect people's tendency to conspiracy thinking to be dependent on their level of institutional trust, whereby people who have low levels of institutional trust are more inclined to conspiracy thinking than people who have high levels of institutional trust.'

Drochon (2018) argues that it is not about representation within the political system itself, but that conspiracy theorists reject the political system as a whole. We formulate the following hypothesis:

Political System Rejection Hypothesis: we expect people's tendency to conspiracy thinking to be dependent on their attitudes towards the political system, whereby people who reject the political system as a whole are more inclined to conspiracy thinking than those who do not reject the political system.i

Drochon (2018) also argues that we should not solely look at political exclusion, but also economic exclusion. There is work linking economic insecurity to belief in conspiracy theories (Goertzel, 1994), but findings are inconclusive (Hollanders, 2018). We formulate the following hypothesis:

Economic Insecurity Hypothesis: we expect people's tendency to conspiracy thinking to be affected by their economic security, whereby people who feel insecure about their economic situation have a higher propensity to conspiracy thinking.

Various studies find that the media also play an important role in conspiracy thinking, as exposure to media messages propagating conspiracy theories leads to greater belief in conspiracy theories not only in the short term (Mulligan and Habel, 2012; Einstein and Glick, 2015; Warner and Neville-Shepard, 2014), but in the long term too (Kim and Cho, 2016). Hollanders (2018) did not find an effect of news exposure but did find that exposure to Fox News is positively related to belief in conspiracy theories, he therefore argues against the use of generic media measures in studies. In particular, studies find that exposure to nonmainstream media that are more likely to contain misinformation, such as blogs, tabloids and YouTube news channels, stimulates conspiracy thinking (Stempel et al., 2017).

Nonmainstream News Hypothesis: we expect people's media use to affect their tendency to conspiracy thinking, the more people expose themselves to nonmainstream media news the more prone they are to conspiracy thinking.

We know that people respond differently to similar phenomena in different contexts and thus this raises the question whether people's proneness to conspiracy thinking is context dependent. We do not assume that people across countries are intrinsically different, but that the way in which their orientations and motivations can manifest themselves differ. For social scientists 
including political scientists, context is an important explanatory factor for studying political attitudes and behaviour across countries and regions. For instance, people's level of political knowledge is not just a reflection of individual characteristics, such as their level of education and political interest, but also their context, as people's access to high quality information about political processes is dependent on the their media environment (Granberg and Holmberg, 1988). Another example is that a voter's propensity to vote cannot just be explained with individual characteristics such as sense of civic duty or political interest, but it is also important to take context characteristics into account, such as the electoral system and the presence of compulsory voting rules (Stockemer, 2017; Singh, 2011).

Due to the focus on single country studies, research on how context affects people's conspiracy thinking has been limited and consequently the theory is somewhat underdeveloped. In the literature we find suggestions that context is important for conspiracy thinking (Uscinski and Parent, 2014) and that conspiracy thinking may be affected by the level of democratization or quality of democracy (Smallpage, 2018; Drochon, 2018), the electoral system (Uscinski and Parent, 2014), or the country's economic wealth and economic inequality (Drochon, 2018). However, these authors are not clear on whether these effects are main effects, iii moderation effects ${ }^{\text {iv }}$ or composition effects. ${ }^{\mathrm{V}}$ Without formulating explicit hypotheses the question of how context matters remains open. We therefore take the freedom to interpret these relationships as both main and moderation effects and explore whether they matter for conspiracy thinking. In addition, we will control in our models for composition effects, i.e. countries matter because the constellation of their population is different.

\section{Data}

The data used in this article was collected as part of the Conspiracy and Democracy project at CRASSH, the University of Cambridge. It was collected online by YouGov using representative samples of the population between 14th August and 31st August 2018. The total number of observations in the dataset is 11,523 . The respondents reside in France $(N=1019)$, Sweden $(N=1009)$, Germany ( $N=2065)$, Great Britain $(N=2171)$, Italy $(N=1012)$, Portugal $(N=1003)$, Poland $(N=1016)$, Hungary ( $N=1005)$ and the United States $(\mathrm{N}=1223)$. The European countries were selected from all European countries to maximize variation in terms of 'deemed relevant' independent factors, such as democratic quality, economic inequality and electoral system. This is a variant of the well-known 'most different cases design' that can be used in the absence of definitive information about their values on outcome variables (Przeworski and Teune, 1970). The US was selected as a baseline category.

To measure conspiracy thinking we offered respondents a number of conspiracy theory statements they could agree or disagree with. The question asked was: 'Which, if any, of the following statements would you say are true? (Please select all that apply)', and respondents could choose the answer options 'Yes' or 'No'. See Table 1 for the surveyed conspiracy theory items, see Table A1 in the supplementary materials for descriptive statistics on these items. Table A1 shows that there is considerable variance in people's belief in specific conspiracy theories between Europe and the US, but also within Europe. Our data confirms the notion that conspiracy belief is widespread as the percentage of people believing in one or more conspiracy theories varies between 52.3 and 84.9 in the European countries studied. This set of conspiracy theory items constitutes the basis of our dependent variable Conspiracy Thinking (see Methods section for more details). The selected conspiracy theory statements are generic in nature and are not strongly connected to the specific societal, economic or political systems of the examined countries; we therefore do not believe that our selection introduces bias in our estimation, however, one can never exclude this. 
Table 1: Survey Items Conspiracy Theories

\begin{tabular}{|l|l|}
\hline Item & \\
\hline A & $\begin{array}{l}\text { Even though we live in what's called a democracy a few people will always run things in } \\
\text { this country anyway. }\end{array}$ \\
\hline B & $\begin{array}{l}\text { Secret plots that harm the nation are more common in this country than in other } \\
\text { countries. }\end{array}$ \\
\hline C & $\begin{array}{l}\text { Humans have made contact with aliens and this fact has been deliberately hidden from the } \\
\text { public. }\end{array}$ \\
\hline D & $\begin{array}{l}\text { The AIDS virus was created and spread around the world on purpose by a secret group or } \\
\text { organisation. }\end{array}$ \\
\hline E & $\begin{array}{l}\text { Regardless of who is officially in charge of governments and other organisations, there is a } \\
\text { single group of people who secretly control events and rule the world together. }\end{array}$ \\
\hline F & The idea of man-made global warming is a hoax that was invented to deceive people. \\
\hline G & $\begin{array}{l}\text { The government is deliberately hiding the truth about how many immigrants really live in } \\
\text { this country. }\end{array}$ \\
\hline H & $\begin{array}{l}\text { The truth about the harmful effects of vaccines is being deliberately hidden from the } \\
\text { public. }\end{array}$ \\
\hline I & $\begin{array}{l}\text { Muslim immigration to this country is part of a bigger plan to make Muslims a majority of } \\
\text { this country's population. }\end{array}$ \\
\hline J & $\begin{array}{l}\text { The official account of the Nazi Holocaust is a lie and the number of Jews killed by the } \\
\text { Nazis during World War Il has been exaggerated on purpose. }\end{array}$ \\
\hline
\end{tabular}

Note: Question asked: 'Which, if any, of the following statements would you say are true? (Please select all that apply)'.

\section{Methods}

\section{Constructing the Conspiracy Thinking Dependent Variable}

For the construction of the dependent variable we conduct a common factor analysis on the basis of tetrachoric correlations as the conspiracy theory items are binary. From the common factor analysis we exclude item $J$ as this item was not asked in all countries (see Table A1 in the supplementary materials). With the remaining 8 items we test the underlying dimensionality of the factor space. Screeplots indicate unambiguously that there is no more than a single underlying factor in all countries studied, with the exception of Hungary. In Hungary one item in particular is responsible for a possible second factor and that is item $\mathrm{G}$ (See Table 1). After excluding this item from the analysis, we find in all countries that the dimensionality of the underlying factor space is one (See Figure 1 in the supplementary materials). On that basis a factor analysis has been conducted, extracting one factor, and factor scores for each individual on that factor have been calculated. We interpret this factor as generic conspiracy thinking and the factor scores can be interpreted as individual scores on the tendency of conspiracy thinking.

By conducting common factor analysis we assume that part of the variance of the separate conspiracy theory items can be accounted for by their shared relevance for conspiracy thinking. This does not mean that all variance in the separate conspiracy items reflect only such a generic tendency of conspiracy thinking. Additionally, each of the items has also unique meaning elements, which are not reflected in the common factor (which reflects a generic tendency of conspiracy thinking). With this approach we capture from the set of conspiracy theory items the part that expresses this generic shared conspiracy thinking and use this as a measurement instrument. ${ }^{\text {vi }}$ This shared conspiracy thinking is captured within the factor loadings of the common factor analysis (See Figure 2 in the supplementary materials for the frequency distribution of conspiracy thinking per country). Robustness analyses showed that the dependent variable constructed is not sensitive to the items selected (See Table A8 and Figure 4 in the supplementary materials). 


\section{Method of Analysis}

Given the hierarchical nature of the data - citizens (level 1) residing within countries (level 2) - the obvious choice would be to estimate a multilevel regression model. However, in this study we opt for running fixed effects OLS regression models on pooled data instead (see Allison 2009). We do so as we are only dealing with 9 countries and because such a small sample size at level 2 leads to biased estimates of second level standard errors when using multilevel modelling (e.g. Maas and Hox, 2004; Bryans and Jenkins, 2016). Some might wonder why we do not conduct 9 separate regression analyses and subsequently compare the coefficients derived from each of these separate regression analyses. This strategy, however, would lead to coefficients that are not comparable because of the differences of distribution of the dependent and independent variables in the separate analyses. Moreover, it would ignore Prezworski and Teune's (1970) dictum that the use of proper names as explanatory factors (in this case names of countries) is theoretically sterile and uninformative. Instead, we want to analyse the information about conspiracy thinking in all countries simultaneously. We structure the regression models in a block recursive manner to take into account the differences in assumed causal antecedence of individual level variables. In our fixed effects OLS regression models country dummies are inserted to control for the dependence of observations at the individual level. In all models the United States serves as the baseline. The statistical analyses are run on 6926 observations due to missing observations on our dependent and independent variables.

\section{Operationalizing the Independent Variables}

Firstly, we include in all models a set of demographic control variables measuring the respondent's sex, age, marital status, employment status and level of education. These demographic controls are operationalized as follows:

Male is a dummy variable measuring the sex of the respondent (1=Male; $0=$ Female).

Age is grouped and measured with a set of dummy variables, namely Under24, Between 25-35,

Between 35-45, Between 45-55 and Over55 (1=Yes; 0=No). Below 24 is the reference category. Unmarried is a dummy variable measuring the respondent's marital status ( $1=$ Unmarried; $0=$ Married).

Unemployed is a dummy variable measuring the respondent's employment status ( $1=$ Unemployed; $0=$ Employed).

Respondents' level of education is measured as a set of dummy variables, respectively Primary Education, Secondary Education and Tertiary Education ( $1=\mathrm{Yes} ; 0=\mathrm{No}$ ). Primary is the reference category.

The other individual level variables included in our models are operationalized as follows: Respondents' ideological position is measured with a set of dummy variables on the basis of people's self-placement in the political spectrum, respectively Left, Centre and Right (1 Yes; 0=No). Respondents who stated to be left wing or slightly left of centre were all labelled left. Respondents who stated to be right wing or slightly right of centre were all labelled right. Left is the reference category in all models.

Ideological Extremity is a dummy variable measuring whether people position themselves at the extremes of the political spectrum (1=Ideologically Extreme; $0=$ Not Ideologically Extreme).

Magical thinking is a dummy variable indicating whether respondents believe that what happens in life is decided by a "higher force", such as God, fate or destiny (1=Strong Magical Thinking; 0=Weak or No Magical Thinking).

Economic Insecurity is a dummy variable indicating whether respondents feel pessimistic about their own financial situation when thinking about the next 12 months ( $1=$ Feels Pessimistic; 0=Does Not Feel Pessimistic).

Representation Within Political System is measured as the extent that respondents feel represented in parliament. Representation Within Political System is a dummy variable indicating 
the extent to which respondents feel that Parliament represents their interests ( $1=$ Feels Badly Represented; 0=Does Not Feel Badly Represented).

Trust in Public Figures is an additive scale that runs from 6 to 24,6 indicating absolutely no trust in public figures and 24 indicating a very high level of trust in public figures. The scale is constructed out of 6 ordinal items that measure trust in senior officials of the EU, senior officials of the US government, government ministers in my country, religious leaders, military leaders in my country and people who run large companies. Mokken scale analysis, which is a stochastic cumulative scaling model for ordinal variables, was used to determine the scalability of the survey items (Mokken, 1971). The overall homogeneity of the scale is .48, which indicates medium scalability (See Table A3 in the supplementary materials for the results of the Mokken scale analysis).

Political System Rejection is a dummy variable indicating whether respondents reject the political system (1 Rejects political system; 0=Does not reject political system). Respondents received the value 1 when they stated that thinking about the political system in their country the statement "The system is broken and it would take a total change of system to put things right" best reflected their view.

Respondents' news sources are measured on the basis of a set of dummy variables indicating respondents' use of this source at least 2-3 times a month to access news, respectively

Newspaper (including online), Television, Radio, Social media, Non-associated News Website/Blog (not associated with a newspaper), Magazines, Podcasts, Email newsletters or RSS feeds (1=Yes; $0=\mathrm{No})$.

The country level variables included in our models are operationalized as follows:

Quality of Democracy is measured using the EUI 2018 Democracy Index of which the scores are weighted averages to an excess of 60 questions of which most are expert assessments. The scores run between 0 and 10 and are rounded to two decimals. vii The score 0 represents a full autocracy and the score 10 represents a full democracy.

Economic Inequality is measured using the most recent GINI index as reported by the World Bank viii, which is a measure of statistical dispersion representing the income or wealth distribution of a nation's residents. The scores run between 0 and 100, where 0 represents perfect equality and 100 represents maximum inequality.

Proportional Representation is measured as a dummy variable ( $1=$ Present; $0=A b s e n t)$. The variable is based on data provided by IDEA Electoral Systems Design Database. ${ }^{\text {ix }}$

Gross Domestic Product is measured nominally expressed in billions of dollars on the basis of the October 2018 International Monetary Fund World Economic Outlook. ${ }^{x}$

\section{Results}

In order to construct the dependent variable Conspiracy Thinking we conducted common factor analysis on the responses to conspiracy theory items (See Methods section for more details). As in all factor analyses, the variance of the conspiracy beliefs can be understood as emanating from three elements, namely (1) generic conspiracy thinking (factors accounting for common variance), (2) item-specific beliefs that are not generic, but idiosyncratic; and (3) random noise. See Table 2 for the variance that generic conspiracy thinking explains of the total variance of these conspiracy theory items per country. The total variance explained by the first factor that reflects generic conspiracy thinking varies between 38.58 per cent (Portugal) and 53.38 per cent (Sweden). The unexplained variance reflects random noise and item-specific elements. The latter, reflects, among other factors, the endorsement of specific conspiracy beliefs by the dominant socio-political discourse in societies' contexts, which is at least in part the result of history, but also the extent to which politicians, political parties, media and other sources of reference in recent times endorse specific conspiracy beliefs. Table 2 also displays the highest and lowest communality scores. So, for instance, the lowest communality in France belongs to item $B$ and it reflects the extent to which individual variation in responses to item $B$ can be understood as emanating from generic conspiracy thinking. 
Table 2: Explained Variance and Lowest/Highest Communality Scores Conspiracy Theory Items

\begin{tabular}{|c|c|c|c|c|c|}
\hline Country & $\begin{array}{c}\text { Explained variance expressed } \\
\text { in \% }\end{array}$ & $\begin{array}{c}\text { Lowest } \\
\text { Communality }\end{array}$ & Item & $\begin{array}{c}\text { Highest } \\
\text { Communality }\end{array}$ & Item \\
\hline France & 42.178 & .302 & $\mathrm{~B}$ & .418 & $\mathrm{D}$ \\
\hline Sweden & 53.384 & .434 & $\mathrm{C}$ & .630 & $\mathrm{D}$ \\
\hline Germany & 44.091 & .193 & $\mathrm{~B}$ & .460 & $\mathrm{E}$ \\
\hline $\begin{array}{c}\text { Great } \\
\text { Britain }\end{array}$ & 50.126 & .339 & $\mathrm{~A}$ & .521 & $\mathrm{~F}$ \\
\hline Italy & 44.739 & .266 & $\mathrm{~A} / \mathrm{B}$ & .578 & $\mathrm{D}$ \\
\hline Portugal & 38.584 & .247 & $\mathrm{~B}$ & .448 & $\mathrm{~F}$ \\
\hline Poland & 42.725 & .189 & $\mathrm{~A}$ & .525 & $\mathrm{D}$ \\
\hline Hungary & 40.515 & .211 & $\mathrm{~A}$ & .561 & $\mathrm{D}$ \\
\hline $\begin{array}{c}\text { United } \\
\text { States }\end{array}$ & 45.892 & .310 & $\mathrm{C}$ & .636 & $\mathrm{I}$ \\
\hline
\end{tabular}

Note: Method: Common Factor Analysis extracting one factor using tetrachoric correlations. Extraction method: Unweighted Least Squares. Second column presents the variance of the total variance of the separate items explained by the first factor. Third and fourth column display the lowest communality score and the item it belongs to. The fifth and sixth column display the highest communality score and the item it belongs to. Communality scores should be interpreted as the extent to which individual variation in responses to that item can be understood as emanating from generic conspiracy thinking.

In this study we explain people's tendency to conspiracy thinking across nine countries on the basis of individual and context characteristics. First of all, contrary to our expectations the variance that can be accounted for by proper names of countries is low, namely 2 per cent (See Table A6 in the supplementary materials). This justifies our choice to focus in our presentation of results on individual-level predictors of conspiracy thinking. Table 2 displays the effect of individual characteristics on conspiracy thinking. Model 1 in Table 2 starts out with the set of sociodemographic variables and shows that male, unemployed and older people have an increased tendency to conspiracy thinking. We find no effect for Secondary education. We do find an effect for Tertiary education, but this effect disappears when controlling for sample composition effects, see Model 3. Therefore, and contrary to much of the literature, we reject our Education Hypothesis. This might lead us to reflect upon what type of skills higher education offers in different national contexts, and how strongly analytical skills, agency and empowerment are linked to higher education, which seem to be more speculative hypotheses than demonstrable theses. It might also make us reflect further on the link education entertains with race, wealth, socialisation and selection effects (Uscinski and Parent, 2014). The sociodemographic variables only explain 1 per cent of the variance of generic conspiracy thinking. 
Table 3 Effects of Individual Characteristics on General Conspiracy Thinking

\begin{tabular}{|c|c|c|c|c|}
\hline & Model 1 & Model 2 & Model 3 & Model 4 \\
\hline \multicolumn{5}{|l|}{ Individual Characteristics } \\
\hline Male & $\begin{array}{l}.085 * * \\
(.021)\end{array}$ & $\begin{array}{l}.088 * * \\
(.021)\end{array}$ & $\begin{array}{l}.092^{* *} \\
(.021)\end{array}$ & .046 \\
\hline Unemployed & $\begin{array}{l}.048^{*} \\
(.024)\end{array}$ & $\begin{array}{c}.033 \\
(.023)\end{array}$ & $\begin{array}{l}.051^{*} \\
(.024)\end{array}$ & .024 \\
\hline Unmarried & $\begin{array}{r}-.0420 \\
(.022) \\
\end{array}$ & $\begin{array}{l}.026 \\
(.021) \\
\end{array}$ & $\begin{array}{l}.033 \\
(.021) \\
\end{array}$ & -.017 \\
\hline Secondary & $\begin{array}{c}.020 \\
(.049) \\
\end{array}$ & $\begin{array}{l}.000 \\
(.04) \\
\end{array}$ & $\begin{array}{c}.014 \\
(.046) \\
\end{array}$ & .006 \\
\hline Tertiary & $\begin{array}{c}-.139 * * \\
(.047)\end{array}$ & $\begin{array}{l}.093^{*} \\
(.045) \\
\end{array}$ & $\begin{array}{r}.075 \\
(.046) \\
\end{array}$ & -.037 \\
\hline Between 25-35 & $\begin{array}{c}.052 \\
(.047)\end{array}$ & $\begin{array}{l}.004 \\
(.045) \\
\end{array}$ & $\begin{array}{c}.011 \\
(.045)\end{array}$ & .004 \\
\hline Between 35-45 & $\begin{array}{l}.125^{* *} \\
(.047)\end{array}$ & $\begin{array}{c}.062 \\
(.045)\end{array}$ & $\begin{array}{c}.074 \\
(.044)\end{array}$ & .028 \\
\hline Between 45-55 & $\begin{array}{l}.134^{* *} \\
(.047)\end{array}$ & $\begin{array}{l}.081^{\circ} \\
(.045)\end{array}$ & $\begin{array}{l}.079^{\circ} \\
(.044)\end{array}$ & .031 \\
\hline Over 55 & $\begin{array}{l}.143^{* *} \\
(.043)\end{array}$ & $\begin{array}{l}.110 * * \\
(.041)\end{array}$ & $\begin{array}{l}.102^{* *} \\
(.041)\end{array}$ & .050 \\
\hline Ideological Extremity & & $\begin{array}{l}.048^{\circ} \\
(.025)\end{array}$ & $\begin{array}{l}.047^{\circ} \\
(.025)\end{array}$ & .020 \\
\hline Centre & & $\begin{array}{l}.078^{* *} \\
(.026)\end{array}$ & $\begin{array}{l}.084^{* *} \\
(.027)\end{array}$ & .036 \\
\hline Right-wing & & $\begin{array}{l}.302 * * \\
(.024)\end{array}$ & $\begin{array}{l}.310^{* *} \\
(.025)\end{array}$ & .144 \\
\hline Magical Thinking & & $\begin{array}{l}.261 * * \\
(.024)\end{array}$ & $\begin{array}{l}.255^{* *} \\
(.025)\end{array}$ & .112 \\
\hline Trust in Public Figures & & $\begin{array}{c}-.034^{* *} \\
(.003)\end{array}$ & $\begin{array}{c}-.036^{* *} \\
(.003)\end{array}$ & -.131 \\
\hline Political System Rejection & & $\begin{array}{l}.226^{* *} \\
(.023)\end{array}$ & $\begin{array}{l}.227^{* *} \\
(.023)\end{array}$ & .110 \\
\hline Feeling Represented in Parliament & & $\begin{array}{l}.069 * * \\
(.023)\end{array}$ & $\begin{array}{l}.069 * * \\
(.024)\end{array}$ & .036 \\
\hline Economic Insecurity & & $\begin{array}{l}.080^{* *} \\
(.024)\end{array}$ & $\begin{array}{l}.086^{* *} \\
(.024)\end{array}$ & .037 \\
\hline Newspapers & & $\begin{array}{c}-.099 * * \\
(.022)\end{array}$ & $\begin{array}{c}-.078^{* *} \\
(.021)\end{array}$ & -.038 \\
\hline Non-associated Website/Blog & & $\begin{array}{l}.080^{* *} \\
(.022)\end{array}$ & $\begin{array}{l}.091^{* *} \\
(.020)\end{array}$ & .043 \\
\hline Social Media & & $\begin{array}{l}.109 * * \\
(.021)\end{array}$ & $\begin{array}{l}.117^{* *} \\
(.021)\end{array}$ & .058 \\
\hline Sweden & & & $\begin{array}{c}-.231^{* *} \\
(.047)\end{array}$ & -.067 \\
\hline France & & & $\begin{array}{c}-.079 \\
(.048) \\
\end{array}$ & -.023 \\
\hline Germany & & & $\begin{array}{c}.231^{* *} \\
(.038)\end{array}$ & -.096 \\
\hline Portugal & & & -.035 & -.011 \\
\hline
\end{tabular}




\begin{tabular}{|c|c|c|c|c|}
\hline & & & $(.043)$ & \\
\hline Poland & & & $\begin{array}{c}-.420^{* *} \\
(.043)\end{array}$ & -.131 \\
\hline Great Britain & & & $\begin{array}{c}.305^{* *} \\
(.072) \\
\end{array}$ & -.048 \\
\hline Italy & & & $\begin{array}{c}.176^{* *} \\
(.044) \\
\end{array}$ & -.056 \\
\hline Hungary & & & $\begin{array}{c}-360^{* *} \\
(.044) \\
\end{array}$ & -.115 \\
\hline Constant & $\begin{array}{l}.787^{* *} \\
(.063) \\
\end{array}$ & $\begin{array}{l}.850 * * \\
(.076) \\
\end{array}$ & $\begin{array}{c}1.023^{* *} \\
(.086) \\
\end{array}$ & \\
\hline Adjusted R2 & .010 & .105 & .126 & \\
\hline AIC & 18013.331 & 17321.171 & 17163.948 & \\
\hline
\end{tabular}

Note: $N=6926$ Method is Fixed Effects OLS Regression Models. Table displays for model 1 to 3 unstandardized regression coefficients. The standard errors are in parentheses. ${ }^{\circ}$ significant at $0.10 .{ }^{*}$ significant at 0.05 .

**significant at 0.01 . For age under 24 is the reference category. For education primary is the reference category. For ideological position leftwing is the reference category. For the country dummies the United States is the reference category. Model 4 displays the $x$-standardized regression coefficients of Model 3 , which means the $x$-variables expressed in standard deviations and the $y$-variable in its original units. $X$-standardized regression coefficients show the relative importance of the independent variables.

Model 2 contains in addition to the sociodemographic variables the hypothesized individuallevel predictors of generic conspiracy thinking. Adding these individual-level predictors significantly improves the fit of the model, which explains 10.5 per cent of the variance of generic conspiracy thinking. The results show that people's ideological position is relevant for people's tendency to conspiracy thinking. The more people position themselves ideologically towards the right of the political spectrum, the stronger their inclination to conspiracy thinking. The variable Ideological Extremity is only significant at 0.10 level. We find that people's propensity to conspiracy thinking is indeed conditional on the extremity of their ideological position, but more so for people who position themselves on the right side of the political spectrum. We find some evidence for our Ideological Extremity Hypothesis. Our finding is in line with recent work that points to ideological asymmetry in conspiracy thinking, i.e. right wing extremists are more likely to engage in conspiracy thinking than left wing extremists, because right wing extremists have personality predispositions, such as low tolerance for uncertainty and a desire for simple solutions, that encourage conspiracy thinking (Linden et al. 2020). In addition to finding people's propensity to conspiracy thinking to be linked to their ideological position, we find conspiracy thinking to be higher for people who score high on magical thinking. The results support our Magical Thinking Hypothesis.

People tend to have a higher propensity to conspiracy thinking when they have less trust in public officials, feel pessimistic about their own financial situation, feel not represented by parliament and reject the political system. We thus find support for our Political Distrust, Economic Insecurity, Representation Within the Political System and Political System Rejection Hypotheses.

Finally, Model 2 also examines the link between people's media use and their propensity to conspiracy thinking. We find reading newspapers to be negatively associated with conspiracy thinking and using social media, websites and blogs that are not associated with newspapers to be positively associated with conspiracy thinking. We did not find any effect for the use of television, radio, magazines, podcasts and email letters or RSS feeds as news source on people's propensity for conspiracy thinking. We did not incorporate these variables in our final model displayed here. We have checked that by omitting these variables the changes in regression coefficients of individuallevel variables are not due to the changes in number of observations on which the analyses are run. See for these robustness tests Table A7 in the supplementary materials. 
We know that people respond differently in specific contexts. When we enter the country dummies to control for the differences between countries (Model 3), we see that the coefficients of the country dummies for Sweden, Germany, Poland, Italy, Great Britain and Hungary are negative and significant. This indicates that people residing in these six countries have on average a slightly lower level of conspiracy thinking than the United States, which is the baseline for the model. No significant differences were found for Portugal and France, these countries have on average a similar level of conspiracy thinking to the United States. Including the country dummies improves the fit of our model and helps us explain 12.6 per cent of the variance, but leaves us with 87.4 per cent unexplained. This suggest that the independent variables evidently carry little explanatory power and thus that the role of demographic and socio-political attitudes identified in our model as well as literature as drivers of generic conspiracy thinking is limited.

To know the relative importance of the independent variables for explaining conspiracy thinking, we standardized the independent variables and not the dependent variable. The $x-$ standardized regression coefficients are calculated on the basis of Model 3, which are displayed in Model 4. For example, the results show that one standard deviation increase in feeling rejected by the system on average results in an .110 increase in conspiracy thinking. The most important variables for explaining generalized conspiracy thinking in our model are Rightwing, Trust in Public Figures, Magical Thinking and System Rejection. We are confident that the findings presented are robust and not driven by a particular country (see for the results of our jackknife sample sensitivity analysis Figures A8 in the supplementary materials).

A further exploration of the main effects and the interactions between context and individual variables (i.e. moderation effects) did not deliver substantial effects, i.e. they did not meet the criterion of at least explaining 1.5 per cent of the 87.4 per cent unexplained variance: the effects were so small in size that they are negligible. The following context variables (Quality of Democracy, Economic Inequality, Proportional Representation, Gross Domestic Product) and the following individual factors (Economic Insecurity, Feeling Represented in Parliament, Political System Rejection) were examined. For reasons of brevity these analyses are not reported here, but they can be found in Table A9 in the supplementary materials.

\section{Conclusion}

This study examined what drives people's tendency towards conspiracy thinking in Europe and the United States. We did so by analysing 2018 survey data of respondents living in Sweden, Germany, Poland, Italy and Hungary, Portugal, France, Great Britain and the United States using representative samples of the population. To our knowledge this is the largest integrated comparative study to date. This study shows that it is possible to study conspiracy thinking comparatively using a set of specific conspiracy theories. We found that the dominant structure of conspiracy beliefs consists of a single common factor, which we labelled conspiracy thinking. This finding has at least two implications. First, that it would be incorrect to consider individual and specific conspiracy theories as only relating to their specific content (e.g., as reflecting simply belief in global warming or belief in the existence of aliens). Second, these findings also imply that individuals' subscription to individual and specific conspiracy beliefs cannot be reduced to only this generic tendency. This therefore leaves room for at least two complementary strands of further research: (a) determinants of and consequences of generic conspiracy thinking; and (b) determinants of and consequences of specific individual conspiracy beliefs, after having controlled for their generic drivers.

At the individual level we found that people who are male, old, unemployed, positioned at the ideologically extremes, who do not feel represented by parliament, feel economically insecure, and use for their news source blogs and non-mainstream social media instead of newspapers have on average a stronger tendency towards conspiracy thinking. We did not find an effect for education, marital status and other media sources. However, the most important predictors for conspiracy thinking are being rightwing, feeling distrust towards public officials, engaging in magical thinking and rejecting the political system. This comparative study thereby demonstrates the 
broader applicability of these factors already identified in some earlier (mostly single country) studies. When one relies on single country studies to replicate earlier work, one cannot rule out that (minor) methodological differences affect the generalizability of the claims made. Such problems do not afflict a comparative study as presented here. Our model - including all these individual level predictors and controlling for country heterogeneity - only explains 12.6 per cent, indicating that many other important predictors of conspiracy thinking were not incorporated. This suggests that the focus on socio-structural variables as the main explanatory factors is perhaps misplaced and that psychological and personality constructs need to be considered further.

The results in this study show surprisingly that only 2 per cent of the variance lies at the country-level, which tells us that to explain generic conspiracy thinking we must look at people's characteristics more so than the characteristics of the country in which they reside. In addition, we find surprisingly that the country-level and cross-level predictors (i.e. moderation effects) suggested in the literature had no substantial effect. This unexpected finding can be explained in several ways. First, the finding can be interpreted to reflect that conspiracy thinking is a purely psychological phenomenon, not or little affected by context (i.e., by social, political and economic characteristics of a country). Second, it is also possible that country characteristics do affect people's propensity to engage in conspiracy thinking but that the measurement instrument used to gauge conspiracy thinking is too abstract to reveal this. This is a likely possibility as all countries included in our sample are very similar in terms of economic wealth, value system and a shared interpretation of contemporary history. A future comparative study should therefore try to expand its scope beyond western, wealthy and democratic countries. Third, country characteristics may moderate people's tendency to conspiracy thinking, but other characteristics than the ones included in our analyses. Future research should try to model other elements of the political and societal context, such as for instance political culture and the quality of the information environment. A further study should develop new and more specific theories on how country differences matter. Therefore, although this study surprisingly finds limited variance at the country level and no substantial effect of the modelled characteristics, this cannot be regarded as definitive support for the notion that context is irrelevant as a moderating factor.

We did find however across the board country effects, namely that people residing in Sweden, Germany, Great Britain, Poland, Italy and Hungary score overall slightly lower on conspiracy thinking that people in the United States. The overall level of conspiracy thinking in France and Portugal was equal to that of the United States. These differences can potentially be explained in two ways. First of all, this can be the result of differences in language. When the conspiracy theory items were translated the items may have received in some languages a somewhat stronger (or, conversely, weaker) meaning. Second, these across the board effects might derive from countryspecific cultural or historical differences that are not captured by the statistical models estimated. However, to test whether these findings are indeed the result of cultural and historical differences it would be helpful to have more than one moment of measurement per country.

By laying the groundwork towards a general theory of conspiracy thinking, this study had offered a first, tentative, step towards these endeavours.

\section{References}

Allison, PD (2009) Fixed Effects Regression Models. Los Angeles, CA: SAGE Publications, Inc. Bogart, LM and Bird, ST (2003) Exploring the relationship of conspiracy beliefs about HIV/AIDS to sexual behaviors and attitudes among African-American adults. Journal of National Medical Association 95 (1): 1057-1065. 
Bruder, M, Haffke, P, Neave, N, Nouripanah, N and Imhoff, R (2013) Measuring Individual Differences in Generic Beliefs in Conspiracy Theories Across Cultures: Conspiracy Mentality Questionnaire, Frontiers in Psychology 4: 225.

Bryan, ML, Jenkins, SP (2016) Multilevel Modelling of Country Effects: A Cautionary Tale, European Sociological Review 32 (1): 3-22.

Camus, JY and Lebourg, N (2017) Far-Right Politics in Europe. Cambridge, MA: Harvard University Press.

Craft, S, Ashley, S and Maksl A (2017) News media literacy and conspiracy theory endorsement. Communication and the Public 2: 388-401.

Darwin, $\mathrm{H}$, Nieves, $\mathrm{N}$ and Holmes, J (2011) Belief in conspiracy theories. The role of paranormal belief, ideation and schizotypy. Personality and Individual Differences 50: 1289-1293.

Dieguez, S, Wagner-Egger, P and Gauvrit, N (2015) Nothing happens by accident, or does it? A low prior for randomness does not explain belief in conspiracy theories. Psychological Science 26 (11): 1762-1770.

Douglas, KM, Uscinski, JE, Sutton, RM, Cichocka, A, Nefes, T, Ang, C S and Deravi, F (2019)

Understanding Conspiracy Theories. Political Psychology. DOI; 10.1111/pops.12568

Douglas, KM, Sutton, RM, Callan, M, Dawtry, RJ, and Harvey, AJ (2016) Someone is pulling the strings: Hypersensitive agency detection and belief in conspiracy theories. Thinking and Reasoning 22: $57-77$.

Drochon, $\mathrm{H}$ (2018) Who believes in conspiracy theories in Great Britain and Europe? In JE Uscinski (Ed.), Conspiracy theories and the people who believe them. New York, NY: Oxford University Press, pp. 337-346.

Enders, A and Smallpage, S (2019) Who Are Conspiracy Theorists? A Comprehensive Approach to Explaining Conspiracy Beliefs, Social Science Quarterly, 100(6), 2017-2032.

Enders, A and Smallpage, S (2018) Polls, Plots, and Party Politics: Conspiracy Theories in Contemporary America. In JE Uscinski (Ed.), Conspiracy theories and the people who believe them. New York, NY: Oxford University Press, pp. 298-318.

Fenster, M (2008) Conspiracy Theories: Secrecy and Power in American Culture. Minneapolis, MN: University of Minnesota Press.

Flynn, DJ, Nyhan, B and Reifer, J (2017) The Nature and Origins of Misperceptions: Understanding False and Unsupported Beliefs About Politics. Political Psychology 38(S1): 127-150.

Freeman, D and Bental, RP (2017) The concomitants of conspiracy concerns. Social Psychiatry and Psychiatric Epidemiology 52(5): 595-604.

Galliford, N and Furnham, A (2017) Individual difference factors and beliefs in medical and political conspiracy theories. Scandinavian Journal of Psychology 58: 422-428.

Goertzel, T (1994) Belief in conspiracy theories. Political Psychology 15 (4): 731-742.

Granberg, D, and Holmberg, S (1988) European monographs in social psychology. The political system matters: Social psychology and voting behavior in Sweden and the United States. Cambridge University Press; Editions de la Maison des Sciences de l'Homme.

Heath, Y, and Gifford, R (2006) Free-Market Ideology and Environmental Degradation: The Case of Belief in Global Climate Change. Environment and Behavior, 38(1): 48-71.

Hogg R, Nkala B, Dietrich J, Collins A, Closson K, Cui Z (2017) Conspiracy beliefs and knowledge about HIV origins among adolescents in Soweto, South Africa. PLOS ONE 12 (2), e0165087. DOI:

10.1371/journal.pone.0165087

Hollander, BA (2018) Partisanship, Individual Differences and News Media Exposure as Predictors of Conspiracy Beliefs. Journalism \& Mass Communication Quarterly 95 (3): 691-713.

Imhoff, D and Bruder, M (2014) Speaking (un-)truth to power: Conspiracy mentality as a generalised political attitude. European Journal of Personality 28 (1): 25-43.

Jasinskaja-Lahti, I and Jetten, J (2019) Unpacking the relationship between religiosity and conspiracy beliefs in Australia, British Journal of Social Psychology, doi.org/10.1111/bjso.12314 
Jost, JT, Glaser, J, Kruglanski, AW, and Sulloway, FJ (2003) Political conservatism as motivated social cognition. Psychological Bulletin 129(3): 339-375.

Judis, J (2016) The Populist Explosion: How the Great Recession Transformed American and European Politics. New York, NY: Columbia Global Reports.

Knight, P (2001) Conspiracy Culture: From Kennedy to the X Files. Abingdon: Routledge.

Knight, P (2002). Conspiracy Nation: The Politics of Paranoia in Postwar America. New York, NY: NYU Press.

Kim, M and Cao, X (2016) The impact of exposure to media messages promoting government conspiracy theories on distrust in government. Evidence from a two-stage randomized experiment. International Journal of Communication 10: 3808-3827.

Krouwel, A; Kutiyski, Y; van Prooijen, J-W, Martinssond, J and Markstedt, E (2017) Does Extreme Political Ideology Predict Conspiracy Beliefs, Economic Evaluations and Political Trust? Evidence From Sweden, Journal of Social and Political Psychology 5(2): 435-462.

Kuklinski, JH, Quirk, PJ, Jerit, J, Schwieder, D and Rich, RF (2000) Misinformation and the currency of Democratic citizenship. Journal of Politics 62(3): 790-816.

Lewandowsky, S, Oberauer, K and GE Gignac (2013) NASA Faked the Moon Landing--Therefore, (Climate) Science Is a Hoax: An Anatomy of the Motivated Rejection of Science, Psychological Science 24(5): 622-633

Leman, PJ and Cinnirella, M (2013) Beliefs in conspiracy theories and the need for cognitive closure. Frontiers in Psychology 4 (378).

Linden, S van der, Panagopoulos, C., Azevedo. F. and Jost, J. T. (2020). The Paranoid Style in American Politics Revisited: An Ideological Asymmetry in Conspiratorial Thinking. Political Psychology, https://doi.org/10.1111/pops.12681

Maas, CJM and JJ Hox (2004) Robustness issues in multilevel regression analysis, Statistica Neerlandica 58 (2): 127-137.

Mancosu, M, Vassallo, S and Vezonni, C (2017) Believing in Conspiracy Theories: Evidence from an Exploratory Analysis of Italian Survey Data, South European Society and Politics 22 (3): 327-344.

Melley, T (2000) Empire of Conspiracy: The Cultural Paranoia in Postwar America. Ithaca, NY: Cornell University Press.

Miller, JM, Saunders, KL and Farhart, CE (2016) Conspiracy endorsement as motivated reasoning: The moderating roles of political knowledge and trust. American Journal of Political Science 60(4): 824-844.

Mokken, RJ (1971) A theory of procedures of scale analysis. The Hague: Mouton Mulligan, K and Habel, P (2013) The implications of fictional media for political beliefs. American Politics Research 41 (1): 122-146.

Nyhan, B and Zeitzoff, T (2018) Conspiracy and misperception belief in the Middle East and North Africa. The Journal of Politics 80: 1400-1404.

Oliver, JE and Wood, TJ (2014) Conspiracy theories and the paranoid style(s) of mass opinion. American Journal of Political Science 58 (4): 952-966.

Przeworski, A and Teune, H (1970) The Logic of Comparative Social Inquiry. New York: Wiley Interscience

Radnitz, S and Underwood, P (2017) Is belief in conspiracy theories pathological? A survey experiment on the cognitive roots of extreme suspicion. British Journal of Political Science 47(1): 113-129.

Siddiqui, N (2018) Who do you believe? Political Parties and Conspiracy Theories in Pakistan, Party Politics DOI: 10.1177/1354068817749777.

Singh, S (2011) How Compelling is Compulsory Voting? A Multilevel Analysis of Turnout. Political Behavior 33: 95-111 (2011).

Smallpage, S (2018) Conspiracy Thinking, Tolerance, and Democracy. In JE Uscinski (Ed.), Conspiracy theories and the people who believe them. New York, NY: Oxford University Press, pp. 187-198. 
Smallpage, S, Drochon, H, Uscinski, JE and Klofstad, C (2020) Who are the Conspiracy Theorists? Demographics and conspiracy theories. In M Butter and P Knight (Eds.), Routledge Handbook of Conpiracy Theories. Abingdon: Routledge, pp. 263-277.

Stempel, C, Hargrove T and Stempel, G H (2007) Media use, social structure and belief in 9/11 conspiracy theories. Journalism \& Mass Communication Quarterly 84 (2): 353-372.

Stockemer, D (2017) What Affects Voter Turnout? A Review Article/Meta-Analysis of Aggregate Research, Government and Opposition, 52 (4), 698-722

Swami, V, and Furnham, A (2012) Examining conspiracist beliefs about the disappearance of Amelia Earhart. The Journal of General Psychology 139: 244-259.

Swami, V (2012) Social psychological origins of conspiracy theories: the case of the Jewish conspiracy theory in Malaysia. Frontiers in Psychology 3, 280.

Swami, V, Voracek, M, Stieger, S, Tran, US, and Furnham, A (2014) Analytic thinking reduces belief in conspiracy theories. Cognition 133: 572-585.

Swami, V, Coles, R, Stieger, S, Pietschnig, J, Furnham, A, Rehim, S and Voracek, M (2011) Conspiracist ideation in Britain and Austria: Evidence of a monological belief system and associations between individual psychological differences and real-world and fictitious conspiracy theories, British Journal of Psychology 102 (3): 443-463.

Yablokov, I (2018) Fortress Russia: Conspiracy theories in the post-Soviet world. Cambridge, United Kingdom: Polity Press.

Uscinski, JE, Klofstadt, C and Atkinson, M D (2016) What drives conspirational beliefs? The role of informational cues and predispositions. Political Research Quarterly 69 (1): 57-71.

Uscinski, JE and Parent, J M (2014) American conspiracy theories. New York, NY: Oxford University Press.

van Prooijen, J-W (2017) Why education predicts decreased belief in conspiracy theories. Applied Cognitive Psychology 31: 50-58.

van Prooijen, J-W and Douglas, KM (2018) Belief in conspiracy theories: Basic principles of an emerging research domain. European Journal of Social Psychology 48: 897-908

van Prooijen, J-W, Krouwel, APM, and Pollet, TV (2015) Political Extremism Predicts Belief in Conspiracy Theories. Social Psychological and Personality Science 6(5): 570-578.

Warner, BR and Neville-Shepard, R (2014) Echoes of a conspiracy: Birthers, truthers, and the cultivation of extremism. Communication Quarterly, 62 (1): 1-17.

Wood, M, Douglas, KM, and Sutton, RM (2012) Dead and alive: Beliefs in contradictory conspiracy theories. Social Psychology and Personality Science. DOI: 10.1177/1948550611434786 


\footnotetext{
' We acknowledge the possibility that the relationship between levels of institutional trust and conspiracy thinking is non-recursive. However, the data does not allow to test rivalling causal interpretations.

ii See also endnote 1.

iii A main effect constitutes here a direct effect of country characteristics on the overall level of conspiracy thinking.

${ }^{i v}$ A moderation effect constitutes here the modification of direction or strength of the relationship between an individual-level predictor and the dependent variable conspiracy thinking, as effectuated by a country characteristic.

${ }^{\vee}$ A composition effect constitutes that countries matter because of the difference in constellation of the countries' population.

vi We run common factor analysis instead of Mokken scale analysis (Mokken, 1971). Mokken scale analysis assumes that the items can be ordered by degree of 'difficulty', which would require the same ordering of items in all countries. We consider this an unrealistic assumption as the variance of the conspiracy items not only reflects generic conspiracy thinking, but also the popularity of items, which we expect to differ between countries.

vii https://www.eiu.com/public/topical report.aspx?campaignid=Democracy2018, visited on 2 December 2019.

viii https://data.worldbank.org/indicator/SI.POV.GINI, visited on 2 December 2019.

ix https://www.idea.int/data-tools/data/electoral-system-design, visited on 2 December 2019.

x https://www.imf.org/external/pubs/ft/weo/2018/02/weodata/download.aspx, visited on 2 December 2019.
} 